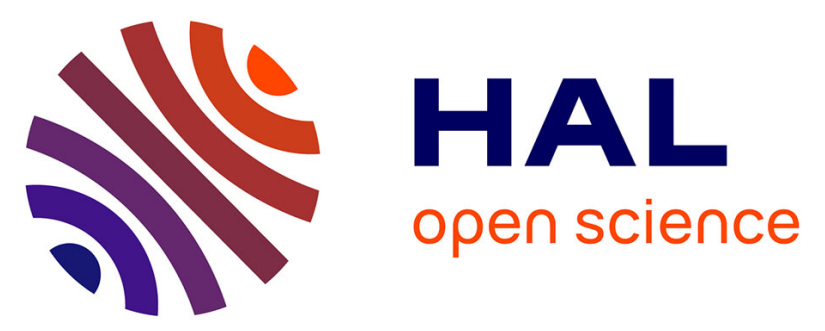

\title{
Tin-Catalyzed Synthesis of 5-Substituted 1H-Tetrazoles from Nitriles: Homogeneous and Heterogeneous procedures
}

Jean-Mathieu Chrétien, Gaelle Kerric, Françoise Zammattio, Nicolas Galland, Michael Paris, Jean-Paul Quintard, Erwan Le Grognec

\section{To cite this version:}

Jean-Mathieu Chrétien, Gaelle Kerric, Françoise Zammattio, Nicolas Galland, Michael Paris, et al.. Tin-Catalyzed Synthesis of 5-Substituted 1H-Tetrazoles from Nitriles: Homogeneous and Heterogeneous procedures. Advanced Synthesis and Catalysis, 2019, 361 (4), pp.747-757. 10.1002/adsc.201801117 . hal-03017577

\section{HAL Id: hal-03017577 \\ https://hal.science/hal-03017577}

Submitted on 21 Nov 2020

HAL is a multi-disciplinary open access archive for the deposit and dissemination of scientific research documents, whether they are published or not. The documents may come from teaching and research institutions in France or abroad, or from public or private research centers.
L'archive ouverte pluridisciplinaire HAL, est destinée au dépôt et à la diffusion de documents scientifiques de niveau recherche, publiés ou non, émanant des établissements d'enseignement et de recherche français ou étrangers, des laboratoires publics ou privés. 


\title{
Tin-Catalyzed Synthesis of 5-Substituted $1 H$-Tetrazoles from Nitriles: Homogeneous and Heterogeneous procedures
}

\author{
Jean-Mathieu Chrétien, ${ }^{\text {a }}$ Gaelle Kerric, ${ }^{a}$ Françoise Zammattio, ${ }^{a}$ Nicolas Galland, ${ }^{\text {a }}$ \\ Michael Paris, ${ }^{\mathrm{b}}$ Jean-Paul Quintard, ${ }^{\mathrm{a}}$ Erwan Le Grognec ${ }^{\mathrm{a}}$ *
}

a Université de Nantes, CNRS, Chimie Et Interdisciplinarité: Synthèse, Analyse et Modélisation (CEISAM), UMR CNRS 6230, Faculté des Sciences et des Techniques; 2, rue de la Houssinière, BP 92208, 44322 Nantes Cedex 3, France. Phone: (+33)-2.76.64.51.84; e-mail: erwan.legrognec@univ-nantes.fr

b Université de Nantes, CNRS, Institut des Matériaux Jean Rouxel (IMN), 2 rue de la Houssinière BP 32229, 44322 Nantes cedex 3, France

\begin{abstract}
The preparation of 5-substituted 1H-tetrazoles was efficiently achieved by reaction of trimethylsilylazide with nitriles using a triorganotin alkoxide precatalyst. The reaction mechanism was first investigated using a homogeneous tributyltin derivative and was explored through experimental investigations and DFT calculations. A heterogeneous version was then developed using a polymer-supported organotin alkoxide and afforded an efficient method for the preparation of tetrazoles in high yields with an easy work-up and a residual tin concentration in the desired products compatible for pharmaceutical applications (less than 10 ppm).
\end{abstract}

Keywords: Azides; Stannanes; Tin; Cycloaddition; Solid-phase synthesis

\section{Introduction}

The tetrazole heterocycle has known an increasing interest in the last decades. Its use concerns many areas of chemistry such as medicinal chemistry, ${ }^{[1],[2]}$ crop protection, ${ }^{[3]}$ explosives, ${ }^{[4]}$ coordination chemistry ${ }^{[5]}$ or organocatalysis. ${ }^{[6]}$ In medicinal chemistry, this interest is focused on the 5-substituted $1 H$-tetrazole unit which is considered as a carboxylic acid isostere for the design of active pharmaceutical ingredients. ${ }^{[7]}$ The huge number of angiotensin II receptor blockers which contain a biphenyltetrazole framework is illustrative of this importance. ${ }^{[8]}$ Therefore, the synthesis and functionalization of 5 -substituted $1 H$-tetrazoles has been widely studied and numerous procedures have been reported and reviewed. ${ }^{[9]}$ Due to the hazards encountered with the use of hydrazoic acid ${ }^{[10]}$ most of them involve the [3+2] cycloaddition of an azide anion to a nitrile in the presence of an acid. The cycloaddition presents a high activation barrier which prompted researchers to use additives or catalysts for milder experimental conditions. For instance, Brönsted or Lewis acids are efficient catalysts for this reaction, as well as metal salts which have been found to be efficient in stoichiometric or sub-stoichiometric quantities. ${ }^{[11]}$ 
A literature survey reveals that one of the most efficient synthesis of 5 -substituted $1 \mathrm{H}$-tetrazoles involve an organotin azide generated in situ from trimethylsilyl azide and dibutyltin oxide, ${ }^{[12]}$ or tributyltin chloride. ${ }^{[13]}$ However the use of organotin reagents in synthetic chemistry is sometimes detrimental for the targeted applications due to the possible toxicity of organotin byproducts. To circumvent this issue, numerous procedures and methodologies have been developed to eliminate tin byproducts from the products and have been reviewed. ${ }^{[14]}$ Most of these methodologies are based on partition methods starting from usual triorganotin reagents, ${ }^{[15]}$ but some others involve highly polar organotin reagents ${ }^{[16]}$ or media $^{[17]}$ as well as perfluorinated ones which highly improve the elimination of organotin by-products. ${ }^{[18]}$

The use of a catalytic amount of organotin reagents ${ }^{[19]}$ or of monoorganotin reagents ${ }^{[20]}$ have also been exploited, but the most efficient approaches to avoid contamination by organotin by-products remain the grafting of the organotin reagent on an appropriate substrate which can be a phosphonium salt, ${ }^{[21]}$ an ionic liquid, ${ }^{[22]}$ an inorganic matrix, ${ }^{[23]}$ or an organic polymer. ${ }^{[14 \mathrm{a}-14 \mathrm{~d}]}$ While the above approaches have demonstrated their efficiency in numerous reactions, their use for the synthesis of 5 -substituted $1 H$-tetrazoles has been overlooked. It is however worth noting that procedures for the synthesis of 5 -substituted $1 H$-tetrazoles involving higher trialkylorganotin derivatives to facilitate the partition between polar products and unpolar tin byproducts have been reported. ${ }^{[24]}$ In the same context, Curran et al have proposed an efficient procedure for the synthesis of 5substituted $1 H$-tetrazoles using a perfluorotin azide and a fluorous/organic liquid-liquid extraction for the purification. ${ }^{[25]}$

Herein, we report the synthesis of 5 -substituted $1 H$-tetrazoles from nitriles through a $[3+2]$ cycloaddition catalyzed by tributyltin azide. This catalyst is generated in situ with tributyltin alkoxide and trimethylsilyl azide. The experimental and theoretical investigations are reported and discussed. The results related to the adaptation of this reaction to a heterogeneous phase reaction involving a polymer-supported catalyst, ${ }^{[26]}$ allowing similar yields and avoiding the drawbacks of the removal of organotin residues are also described.

\section{Results and Discussion}

Scope and limitations of the reaction catalyzed by a tributyltin derivative. We set out to explore the synthesis of 5-substituted $1 H$ tetrazoles 3 resulting from the addition of an organotin azide on a nitrile 1 . Our investigations started from contributions involving trimethylsilyl azide $\left(\mathrm{Me}_{3} \mathrm{SiN}_{3}\right)$ and dibutyltin oxide considered in stoichiometric or in catalytic amount. ${ }^{[12]}$ We focused on a dibutyltin oxide surrogate readily graftable on polymer. At this stage, we assumed that trialkyltin alkoxides could be valuable precursors of triorganotin azides and started our investigations by this consideration. Tributyltin methoxide $\mathbf{2 a}$ and tributyltin ethoxide $\mathbf{2 b}$ were prepared according to the literature, starting from bis(tributyltin) oxide and dimethyl or diethylcarbonate (scheme 1). ${ }^{[27]}$

$$
\begin{aligned}
& \begin{array}{ccc}
\left(\mathrm{Bu}_{3} \mathrm{Sn}\right)_{2} \mathrm{O} \quad \stackrel{(\mathrm{RO})_{2} \mathrm{CO}}{110^{\circ} \mathrm{C}, 18 \mathrm{~h}} \quad \mathrm{Bu}_{3} \mathrm{SnOR} \\
\mathrm{R}=\mathrm{Me}, 2 \mathrm{a}, 93 \%
\end{array} \\
& \mathrm{R}=\mathrm{Et}, \mathbf{2 b}, \mathbf{9 6 \%}
\end{aligned}
$$

Scheme 1. Preparation of tributyltin alkoxides $\mathbf{2 a}$ and $\mathbf{2 b}$. 
These tributyltin alkoxides were considered for the synthesis of 5-phenyl $1 H$ tetrazole 3a in different solvents starting from benzonitrile. The results obtained in this preliminary study using $10 \mathrm{~mol} \%$ of $\mathbf{2 a}$ or $\mathbf{2 b}$ are reported in Table 1. When the reaction was carried out in toluene (entries 1 and 2), 5-phenyl 1H-tetrazole 3a was obtained in low yields, regardless the tin catalyst although this solvent was extensively considered previously (entries 1 and 2). ${ }^{[12 \mathrm{~d}]}$ Similar results were observed when 1,2-dimethoxyethane was used (entries 3 and 4 ) and only moderate yields were obtained with 1,4-dioxane (entries 5 and 6). By considering polar solvents with high boiling points, high yields were obtained with DMF (entries 7 and 8), while NMP afforded only moderate yields (entries 9 and 10). Finally, yields were significantly improved using dibutylether $\left(\mathrm{Bu}_{2} \mathrm{O}\right)$ as solvent (entries 11 and 12). Through these runs, we also observed that the presence of water, even in small quantities, had a dramatic negative effect on the yield as previously reported. ${ }^{[28]}$ These results confirmed that trialkyltin alkoxides can act as precatalysts for the synthesis of 5 -substituted $1 \mathrm{H}$-tetrazoles. This screening also highlights that compound 2a is more efficient than 2b. Moreover, control experiments with dibutyltin oxide afforded lower yields in similar experimental conditions (entries 13 and 14). Similarly, when $\mathrm{Bu}_{3} \mathrm{SnCl}$ was considered either with $\mathrm{Me}_{3} \mathrm{SiN}_{3}$ or with $\mathrm{NaN}_{3}$, poor yields were obtained (entries 15 and 16). The latter results are in good agreement with a previous work reporting that a large excess ( 2.5 equiv) of both tributyltin chloride and sodium azide is required to obtain yields around $80 \%{ }^{[13 b]}$

Table 1. Effect of solvent and catalyst on the formation of tetrazole 3a from 1a.

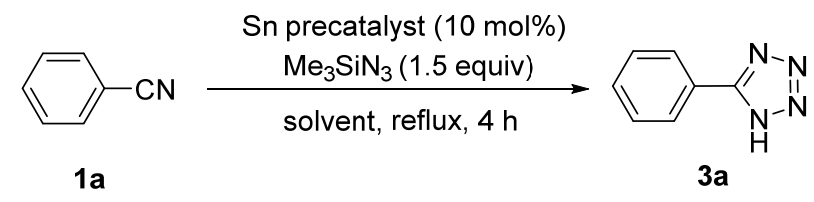

\begin{tabular}{|c|c|c|c|c|}
\hline Entry & $\begin{array}{c}\mathrm{Sn} \\
\text { precatalyst }\end{array}$ & Solvent & $\mathrm{T}\left({ }^{\circ} \mathrm{C}\right)$ & Yield (\%) \\
\hline 1 & $\mathrm{Bu}_{3} \mathrm{SnOMe}$ & toluene & 110 & 15 \\
\hline 2 & $\mathrm{Bu}_{3} \mathrm{SnOEt}$ & toluene & 110 & 14 \\
\hline 3 & $\mathrm{Bu}_{3} \mathrm{SnOMe}$ & DME & 85 & 24 \\
\hline 4 & $\mathrm{Bu}_{3} \mathrm{SnOEt}$ & DME & 85 & 11 \\
\hline 5 & $\mathrm{Bu}_{3} \mathrm{SnOMe}$ & 1,4-dioxane & 100 & 44 \\
\hline 6 & $\mathrm{Bu}_{3} \mathrm{SnOEt}$ & 1,4-dioxane & 100 & 42 \\
\hline 7 & Bus SnOMe & DMF & 150 & 93 \\
\hline 8 & $\mathrm{Bu}_{3} \mathrm{SnOEt}$ & DMF & 150 & 57 \\
\hline 9 & $\mathrm{Bu}_{3} \mathrm{SnOMe}$ & NMP & 150 & 53 \\
\hline 10 & $\mathrm{Bu}_{3} \mathrm{SnOEt}$ & NMP & 150 & 47 \\
\hline 11 & $\mathrm{Bu}_{3} \mathrm{SnOMe}$ & $\mathrm{Bu}_{2} \mathrm{O}$ & 140 & 99 \\
\hline 12 & BusSnOEt & $\mathrm{Bu}_{2} \mathrm{O}$ & 140 & 85 \\
\hline 13 & $\left(\mathrm{Bu}_{2} \mathrm{SnO}\right)_{\mathrm{n}}$ & DMF & 150 & 45 \\
\hline 14 & $\left(\mathrm{Bu}_{2} \mathrm{SnO}\right)_{\mathrm{n}}$ & $\mathrm{Bu}_{2} \mathrm{O}$ & 140 & 73 \\
\hline 15 & $\mathrm{Bu}_{3} \mathrm{SnCl}$ & $\mathrm{Bu}_{2} \mathrm{O}$ & 140 & 26 \\
\hline 16 & $\mathrm{Bu}_{3} \mathrm{SnCl}$ & $\mathrm{Bu}_{2} \mathrm{O}$ & 140 & 18 \\
\hline
\end{tabular}

Then, precatalyst loading tests were performed with 2, 5 and $10 \mathrm{~mol} \%$ of $\mathbf{2 a}$ in DMF or in $\mathrm{Bu}_{2} \mathrm{O}$ and it appeared that $10 \mathrm{~mol} \%$ of catalyst was necessary to obtain yields over $90 \%$ after $4 \mathrm{~h}$ (Table 2 ). When reducing the amount of $\mathbf{2 a}$ to 5 and $2 \mathrm{~mol} \%$, yields in 3a significantly decreased while control experiments confirmed that no reaction 
occurred in the absence of $\mathbf{2 a}$. Furthermore, when $\mathrm{Me}_{3} \mathrm{SiN}_{3}$ was replaced by $\mathrm{NaN}_{3}$, the yield was found to be low $(9 \%$, entry 9$)$.

At this stage, the scope of the reaction for substituted benzonitriles was investigated using $\mathbf{2 a}$ as precatalyst in DMF at $150{ }^{\circ} \mathrm{C}$ and in $\mathrm{Bu}_{2} \mathrm{O}$ at $140{ }^{\circ} \mathrm{C}$. The results reported in Table 3, revealed that a large variety of substituents were found to be compatible with the procedure. Both electron-donating and electron-withdrawing groups on the aryl moiety afforded efficiently tetrazole products $\mathbf{3 a - 3}$.

Table 2. Effect of precatalyst loading and solvent on the conversion of benzonitrile into tetrazole 3a.

\begin{tabular}{|c|c|c|c|c|}
\hline & $\begin{array}{l}\mathrm{SnOMe}, 2 \mathrm{a}(\mathrm{x} \\
\mathrm{e}_{3} \mathrm{SiN}_{3}(1.5 \mathrm{eq} \\
\text { olvent, } \Delta, 4 \mathrm{~h}\end{array}$ & \multicolumn{2}{|c|}{$3 a$} \\
\hline Entry & Solvent & $\mathrm{x}(\mathrm{mol} \%)$ & $\mathrm{T}\left({ }^{\circ} \mathrm{C}\right)$ & Yield $(\%)$ \\
\hline 1 & DMF & 0 & 150 & 0 \\
\hline 2 & DMF & 2 & 150 & 48 \\
\hline 3 & DMF & 5 & 150 & 51 \\
\hline 4 & DMF & 10 & 150 & 93 \\
\hline 5 & $\mathrm{Bu}_{2} \mathrm{O}$ & 0 & 140 & 0 \\
\hline 6 & $\mathrm{Bu}_{2} \mathrm{O}$ & 2 & 140 & 32 \\
\hline 7 & $\mathrm{Bu}_{2} \mathrm{O}$ & 5 & 140 & 76 \\
\hline 8 & $\mathrm{Bu}_{2} \mathbf{O}$ & 10 & 140 & 99 \\
\hline 9 & $\mathrm{Bu}_{2} \mathrm{O}$ & 10 & 140 & $9^{[\mathrm{a}]}$ \\
\hline
\end{tabular}

Aromatic nitriles bearing electron-donating groups like $p$-Me, $p$-OMe, $p$-NEt $\mathrm{N}_{2}$ afforded good yields of products 3b, 3c or 3d. Similarly, aromatic nitriles bearing electron withdrawing groups ( $m-\mathrm{OMe}, p-\mathrm{NO}_{2}, m-\mathrm{Cl}, p-\mathrm{Cl}, m-$ $\mathrm{CF}_{3}$ ) afforded excellent yields in products $\mathbf{3 f}, \mathbf{3 g}, \mathbf{3 h}, \mathbf{3 i}$ or $\mathbf{3 j}$. In addition, 4-hydroxybenzonitrile gave the corresponding tetrazole $\mathbf{3 k}$ in good yield, while methyl 4-cyanobenzoate afforded 4-(1H-tetrazol-5-yl)benzoic acid $\mathbf{3 l}$ due to the hydrolysis of the ester function during the workup procedure. On the other hand, moderate to low yields were obtained with ortho substituted aromatic nitriles (tetrazoles $\mathbf{3 m}, \mathbf{3 n}, \mathbf{3 o}$ ), indicating that the reaction is sensitive to the steric hindrance near the nitrile group. However, 1-naphtonitrile where the effective hindrance on the $\alpha$-position is lower and the activation of the nitrile higher when compared to ortho biphenyl nitrile, afforded high yield (3p). Finally, we investigated the reactivity of aliphatic nitriles and found that the procedure was also efficient for these substrates. Phenylacetonitrile, valeronitrile and nonanenitrile furnished the desired tetrazoles 3q-s in good to moderate yields in the same reaction conditions, underlining the efficiency of the methodology since these substrates are poorly reactive in this type of reaction with other methods. ${ }^{[11 e]}$

Experimental investigations of the reaction mechanism. At this stage, further investigations were conducted in order to collect insights on the reaction mechanism. The reactive species supposed to be formed in this reaction is tributyltin azide $\left(\mathrm{Bu}_{3} \mathrm{SnN}_{3}\right)$. Therefore, its synthesis was carried out using a described procedure starting from tributyltin halide and $\mathrm{NaN}_{3}$ (Table 4). ${ }^{[29]}$ Due to the low solubility of $\mathrm{NaN}_{3}$ in organic solvents, different experimental conditions were considered for this reaction. A careful monitoring of the reaction using ${ }^{119} \mathrm{Sn}$ NMR revealed a complete conversion of $\mathrm{Bu}_{3} \mathrm{SnX}$ to $\mathrm{Bu}_{3} \mathrm{SnN}_{3}$ after $18 \mathrm{~h}$ at room temperature. When $\mathrm{NaN}_{3}$ was replaced by $\mathrm{Me}_{3} \mathrm{SiN}_{3}$, the reaction was found to proceed faster due to the higher miscibility of $\mathrm{Me}_{3} \mathrm{SiN}_{3}$ with $\mathrm{Bu}_{3} \mathrm{SnCl}_{\text {, and }}$ 
conversion to $\mathrm{Bu}_{3} \mathrm{SnN}_{3}$ was observed at room temperature in a few minutes. After distillation, $\mathrm{Bu}_{3} \mathrm{SnN}_{3}$ was obtained in $95 \%$ yield and characterized by FT-IR and ${ }^{119} \mathrm{Sn}$ NMR. Interestingly, the ${ }^{119} \mathrm{Sn}$ chemical shift was found to be strongly solvent dependent as reported in table 4. These differences in chemical shifts can be explained by the modification of the tin hybridization from $\mathrm{sp}^{3}$ to $\mathrm{sp}^{3} \mathrm{~d}$ due to intermolecular interactions between the tin atom and a solvent heteroatom or a nitrogen atom of a second molecule of $\mathrm{Bu}_{3} \mathrm{SnN}_{3} .{ }^{[30]}$

Table 3. Synthesis of 5-substituted $1 H$-tetrazoles promoted by $\mathrm{Bu}_{3} \mathrm{SnOMe}, \mathbf{2 a}$.

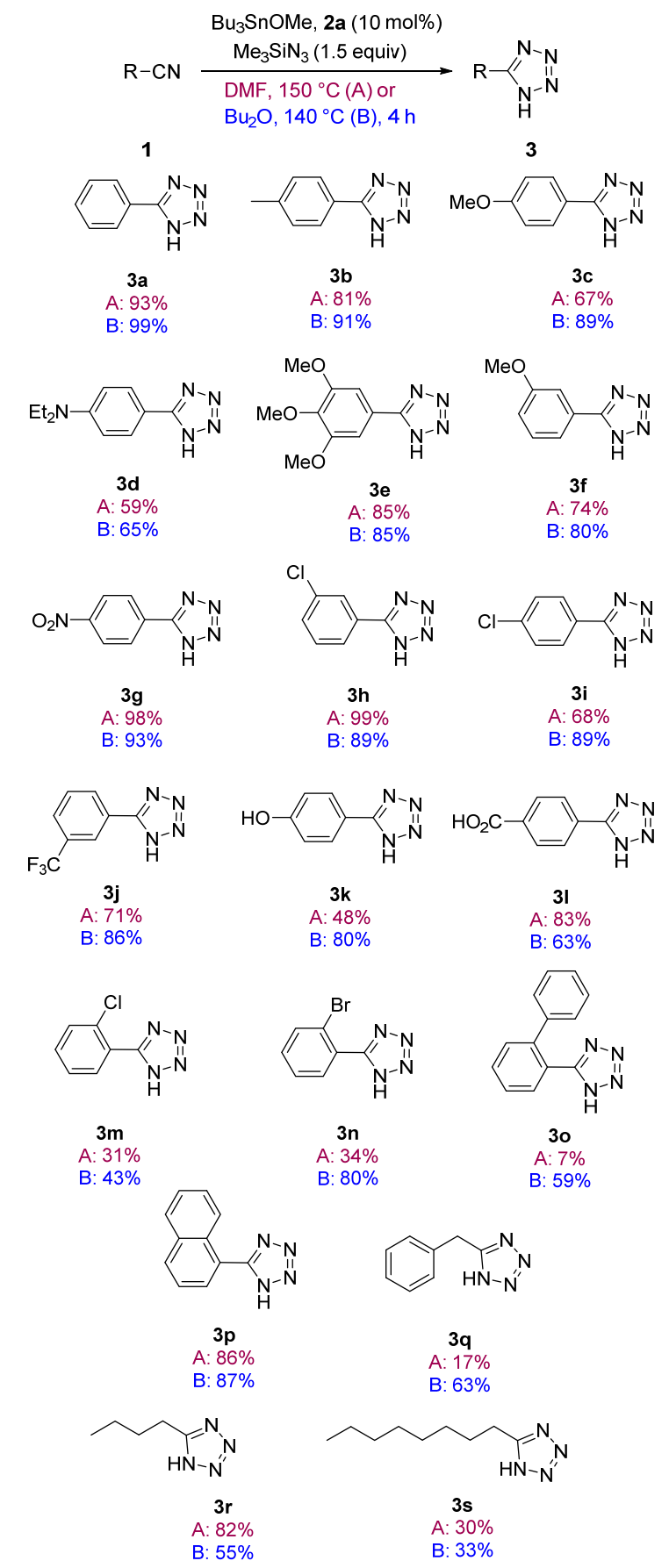


Table 4. Solvent dependence of ${ }^{119} \mathrm{Sn}$ NMR chemical shift for $\mathrm{Bu}_{3} \mathrm{SnN}_{3}$.

\begin{tabular}{|c|c|c|c|}
\hline \multicolumn{2}{|c|}{$\mathrm{Bu}_{3} \mathrm{SnX}$} & \multicolumn{2}{|c|}{$\underset{\text { solvent }}{\longrightarrow} \mathrm{Bu}_{3} \mathrm{SnN}_{3}+\mathrm{NaX}$} \\
\hline Entry & $\mathrm{Bu}_{3} \mathrm{SnX}$ & Solvent & $\delta^{119} \mathrm{Sn}\left(\mathrm{Bu}_{3} \mathrm{SnN}_{3}\right)(\mathrm{ppm})^{[\mathrm{a}]}$ \\
\hline 1 & $\mathrm{Bu}_{3} \mathrm{SnI}$ & without & 76 \\
\hline 2 & $\mathrm{Bu}_{3} \mathrm{SnI}$ & $\begin{array}{c}\text { DMF- } \\
\text { d7 }\end{array}$ & -51 \\
\hline 3 & $\mathrm{Bu}_{3} \mathrm{SnI}$ & THF-d8 & 66 \\
\hline 4 & $\mathrm{Bu}_{3} \mathrm{SnCl}$ & without & 63 \\
\hline 5 & $\mathrm{Bu}_{3} \mathrm{SnCl}$ & $\mathrm{C}_{6} \mathrm{D}_{6}$ & 103 \\
\hline 6 & $\mathrm{Bu}_{3} \mathrm{SnCl}$ & $\mathrm{CDCl}_{3}$ & 111 \\
\hline
\end{tabular}

When the reaction between $\mathrm{Bu}_{3} \mathrm{SnOMe}$ and $\mathrm{Me}_{3} \mathrm{SiN}_{3}$ was carried out without any solvent at $25^{\circ} \mathrm{C}$, a NMR monitoring by ${ }^{119} \mathrm{Sn}$ NMR and ${ }^{29} \mathrm{Si}$ NMR conducted at room temperature reveals the occurrence of a partial exchange after 1 hour (Scheme 2, eq 1). Indeed, two signals were observed on both spectra, corresponding to $\mathrm{Bu}_{3} \operatorname{SnOMe}(\delta=113 \mathrm{ppm})$ and $\mathrm{Bu}_{3} \mathrm{SnN}_{3}(\delta=63 \mathrm{ppm})$ on ${ }^{119} \mathrm{Sn}$ NMR spectrum, and to $\mathrm{Me}_{3} \mathrm{SiN}_{3}(\delta=16.6 \mathrm{ppm})$ and $\mathrm{Me}_{3} \mathrm{SiOMe}(\delta=19.5 \mathrm{ppm})$ on ${ }^{29} \mathrm{Si}$ NMR spectrum. In addition the FT-IR spectrum clearly exhibits the characteristic band at $2065 \mathrm{~cm}^{-1}$ ascribed to the vibration $v_{a s} \mathrm{~N}_{3}$ in $\mathrm{Bu}_{3} \mathrm{SnN}_{3} .{ }^{[31]}$ Furthermore, the reaction between benzonitrile and tributyltin azide does not occur at room temperature and requires an appropriate heating ( $4 \mathrm{~h}$ at $140{ }^{\circ} \mathrm{C}$ ) to afford $N$-tributylstannyl 5-phenyl $1 H$-tetrazoles 3a-Sn (Scheme 2, eq 2). ${ }^{[12 \mathrm{a}],[32]}$ After $4 \mathrm{~h}$ at $140{ }^{\circ} \mathrm{C}$, the solvent-free reaction afforded quantitatively 3a-Sn, which was isolated and characterized in spite of its sensitivity to hydrolysis. Note that well defined signals were observed in ${ }^{13} \mathrm{C}$ NMR spectrum, while broader signals were observed in ${ }^{1} \mathrm{H}$ and ${ }^{119} \mathrm{Sn}$ NMR spectra, a result which is in agreement with the possible intermolecular associations and metallotropy. ${ }^{[32]}$ All attempts to isolate the silylated tetrazole (intermediates 3aSi) obtained by reaction between 3a-Sn and $\mathrm{Me}_{3} \mathrm{SiN}_{3}$ were unsuccessful (Scheme 2, eq 3). However, when the reaction was performed in a NMR tube under inert atmosphere, the ${ }^{29} \mathrm{Si}$ NMR spectrum exhibits a signal at 10.2 ppm, different from the chemical shifts of $\mathrm{Me}_{3} \mathrm{SiN}_{3}(16.6 \mathrm{ppm})$ and $\mathrm{Me}_{3} \mathrm{SiOMe}(19.5 \mathrm{ppm})^{[33]}$ which could be assigned to intermediates $\mathbf{3 a - S i}$.

Based on these results and taking into account previous proposed mechanism, ${ }^{[12 \mathrm{~d}]}$ we considered the catalytic cycle described in scheme 3 as a plausible one. First the precatalyst 2a reacts with trimethylsilyl azide to afford tributylstannyl azide which is the active species of the reaction. This reaction proceeds at room temperature and therefore cannot be the limiting step. 


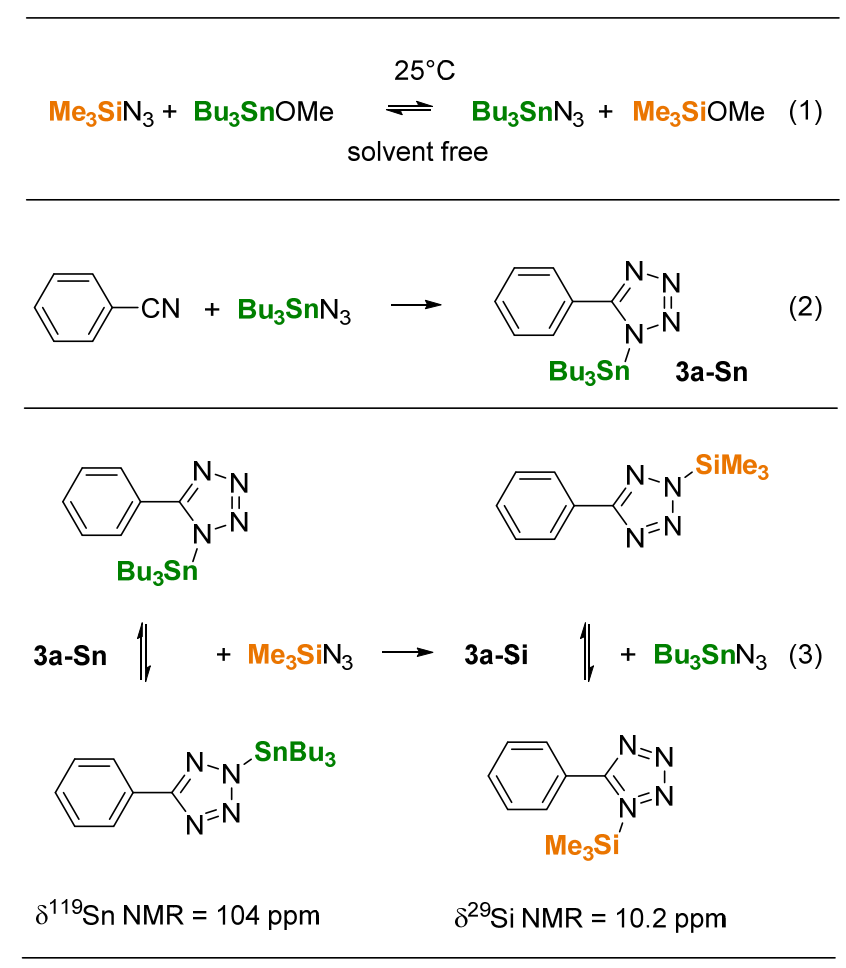

Scheme 2. Tributyltin azide: its generation and its reactivity with benzonitrile.

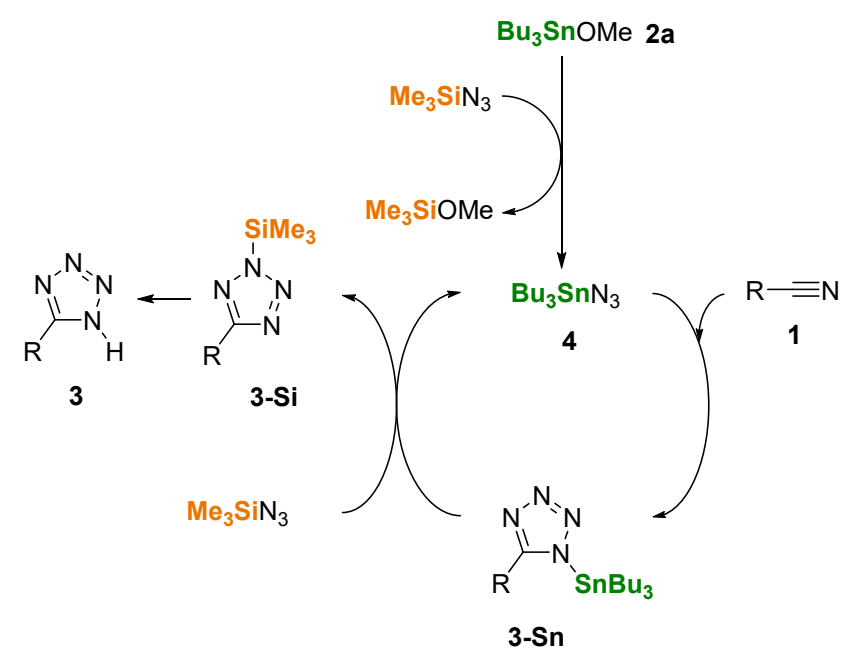

Scheme 3. Proposed mechanism for the synthesis of 5 -substituted $1 H$-tetrazoles promoted by $\mathrm{Bu}_{3} \mathrm{SnOMe}$.

The reaction between tributyltin azide and nitrile exhibits a higher energetic barrier to lead to adducts $\mathbf{3 a - S n}$. The latter reacts with another molecule of trimethylsilyl azide to give intermediates 3a-Si with concomitant regeneration of $\mathrm{Bu}_{3} \mathrm{SnN}_{3}$ and finally a protonolysis of $\mathbf{3 a - S i}$ affords the 5-phenyl $1 \mathrm{H}$-tetrazole $\mathbf{3 a}$. 

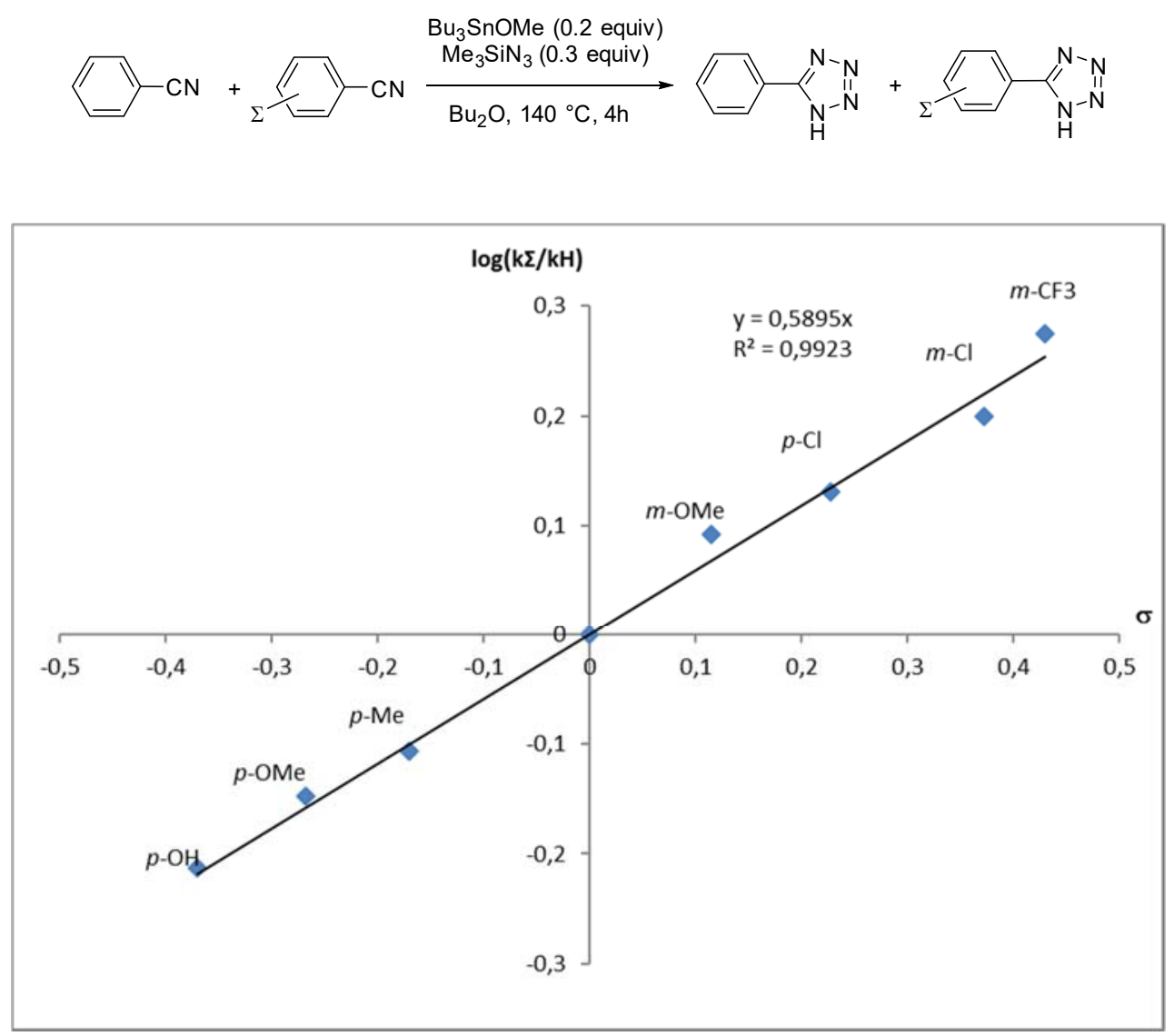

Figure 1. Hammett plot for reactivity of substituted benzonitriles with in situ generated tributyltin azide.

At this stage, it remains to clarify the intimate mechanism of the rate determining step of the reaction in order to establish its synchronous or non-synchronous character. For this purpose, we have conducted additional experimental investigations. We have carried out competitive experiments between benzonitrile and meta- or para- substituted benzonitriles in order to establish a Hammett relationship based on the relative kinetics of these reactions. These experiments have been carried out according to the Doering-Henderson approximation (reactant/substrate ratio $=1 / 5)^{[34]}$ to ensure accurate measurements in line with kinetics for Hammett relationship. ${ }^{[35]}$ As suggested from yields given in Table 3, benzonitriles substituted by strong electronwithdrawing groups exhibited a higher reactivity when compared to those substituted by electron releasing ones. As shown in Figure 1, a Hammett $\rho . \sigma$ relationship was obtained with a calculated $\rho$-value of +0.58 . This positive $\rho$-value is indicative of a slight negative charge at the benzylic carbon in the transition state, a result in agreement with a nucleophilic attack of the azide on the carbon of the nitrile group probably combined with an electrophilic assistance of tin on the nitrogen atom of the nitrile.

DFT investigations of the reaction mechanism. Further investigations have been performed by means of quantum mechanical calculations at the BMK/cc-pVDZ level of theory. The presented free energies are corrected from solvent effects and are computed for the $140{ }^{\circ} \mathrm{C}$ and $1 \mathrm{~mol} \cdot \mathrm{L}^{-1}$ standard state. At first, we considered the mechanism of the reaction between $\mathrm{Me}_{3} \mathrm{SiN}_{3}$ and benzonitrile in the absence of catalyst. In agreement with the pioneering computational work of Noodleman and Sharpless, ${ }^{[36]}$ dealing with the elucidation of the mechanisms 
of tetrazole formation by addition of azide to nitriles, two different pathways have been characterized which correspond to the formation of either 1,5 or 3,5-regioisomers 3a-Si (scheme 4). Both (A) and (B) reaction pathways exhibit an energy barrier, corresponding to a concerted [3+2] cycloaddition. The respective values, $46.1 \mathrm{kcal} \mathrm{mol}^{-1}$ and $48.4 \mathrm{kcal} \mathrm{mol}^{-1}$ with respect to the reactants, are calculated in good agreement with previous DFT values obtained by Kappe et al. ${ }^{[37]}$ for the cycloaddition of $\mathrm{Me}_{3} \mathrm{SiN}_{3}$ with acetonitrile. These high energy barriers are consistent with the absence of reaction at $140{ }^{\circ} \mathrm{C}$ between $\mathrm{Me}_{3} \mathrm{SiN}_{3}$ and benzonitrile although the reaction is predicted exergonic $\left(\Delta \mathrm{G}_{\mathrm{R}}<0\right)$.

(A)

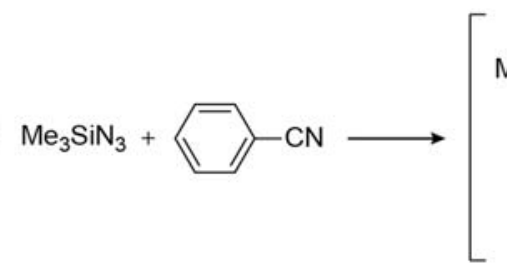

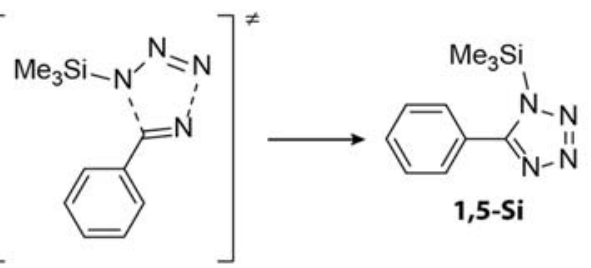

(B)

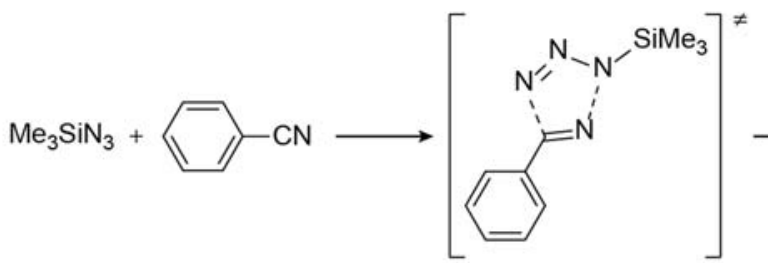

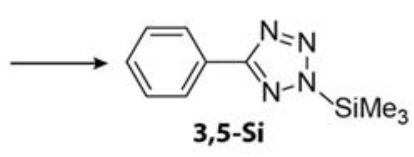

3,5-Si
$\Delta \mathrm{G}^{*}=+46.1 \mathrm{kcal} \mathrm{mol}^{-1}$

$\Delta G_{R}=-13.1 \mathrm{kcal} \mathrm{mol}^{-1}$

$\Delta \mathrm{G}^{*}=+48.4 \mathrm{kcal} \mathrm{mol}^{-1}$

$\Delta G_{R}=-19.9 \mathrm{kcal} \mathrm{mol}^{-1}$

Scheme 4. Evaluation of the activation energy for uncatalyzed cycloaddition of $\mathrm{Me}_{3} \mathrm{SiN}_{3}$ to benzonitrile (computed at the BMK/cc-pVDZ level of theory).

Then, we studied the influence of the triorganotin alkoxide on the reaction between $\mathrm{Me}_{3} \mathrm{SiN}_{3}$ and benzonitrile. The catalytic cycle described in scheme 3 was notably investigated. Computational considerations prompted us to use $\mathrm{Me}_{3} \mathrm{SnN}_{3}$ as model compound in order to mimic $\mathrm{Bu}_{3} \mathrm{SnN}_{3}$. In principle, $\mathrm{Me}_{3} \mathrm{SnN}_{3}$ can react with benzonitrile according to the (A) and (B) mechanisms depicted for the direct reaction with $\mathrm{Me}_{3} \mathrm{SiN}_{3}$. Indeed, a possible reaction pathway involving a synchronous cycloaddition, as in (A), and leading to a 1,5-disubstituted 3-Sn species was evidenced (Figure 2). However, the predicted energy barrier, $45.5 \mathrm{kcal} \mathrm{mol}^{-1}$ with respect to the reactants, is close to that calculated for the uncatalyzed reaction, which suggests that this process cannot occur in our experimental conditions. In agreement with the work of Kappe et al. on tin-catalyzed addition of $\mathrm{Me}_{3} \mathrm{SiN}_{3}$ to acetonitrile, ${ }^{[37]}$ we found that the (B) reaction pathway is markedly modified (Figure 2). A stepwise mechanism emerges, beginning with the approach of the benzonitrile nitrogen on the acidic tin atom of $\mathrm{Me}_{3} \mathrm{SnN}_{3}$, while the nitrile carbon is activated for the addition of the azide. This process leads to the open-chain reaction intermediate RI B1, through the transition state TS B1 computed $34.9 \mathrm{kcal}^{\mathrm{mol}} \mathrm{l}^{-1}$ above the reactants., which is the ratedetermining step of the reaction. The next steps are part of the ring-closing process. The latter involves two smaller energy barriers (25.6 and $30.3 \mathrm{kcal} \mathrm{mol}^{-1}$ with respect to the reactants), a further open-chain reaction intermediate (RI B2), and results in the formation of a 1,5-disubstituted 3-Sn species (with a reaction free energy of $-14.6 \mathrm{kcal} \mathrm{mol}^{-1}$ ). According to eq. 3 of scheme 2, the latter would react with $\mathrm{Me}_{3} \mathrm{SiN}_{3}$ to afford the 3a-Si species, while recovering the catalyst. Note that such efficient recovery process of the catalyst was already disclosed for organotin-catalyzed cycloaddition between $\mathrm{Me}_{3} \mathrm{SiN}_{3}$ and acetonitrile. ${ }^{[37]}$ 
Thus, it exists a stepwise mechanism that (i) lowers significantly the activation free energy, by $11.2 \mathrm{kcal} \mathrm{mol}^{-}$ ${ }^{1}$ with respect to the uncatalyzed reaction, and (ii) could explain the observed high yield for the reaction between $\mathrm{Me}_{3} \mathrm{SiN}_{3}$ and benzonitrile when $\mathrm{Bu}_{3} \mathrm{SnN}_{3}$ was in situ generated. Additional clues are provided through the comparison between observed trends for substituted benzonitriles and those predicted by DFT calculations. We assumed that the first step of the (B) pathway control the reaction kinetic. Experimentally, the reaction with the meta-chlorobenzonitrile proceeds 1.6 faster than the one with unsubstituted benzonitrile, and the reaction with the para-hydroxybenzonitrile is 1.6 slower than the one with unsubstituted benzonitrile. We have computed the energy barriers corresponding to the activation of the nitrile in the meta-chlorobenzonitrile $\left(34.2 \mathrm{kcal} \mathrm{mol}^{-1}\right)$ and in the para-hydroxybenzonitrile $\left(35.5 \mathrm{kcal} \mathrm{mol}^{-1}\right)$. According to the transition state theory and the resulting Eyring's equation, ${ }^{[38]}$ these values lead to a rate constant for the meta-chlorobenzonitrile 2.3 larger than for the unsubstituted benzonitrile, and a rate constant for the para-hydroxybenzonitrile 2.1 smaller than for the unsubstituted benzonitrile. There is clearly a good agreement with experiments, which supports the proposed mechanism for the tin-catalyzed formation of 5-substituted $1 H$-tetrazoles.

Reaction catalyzed by a polymer-supported tin derivative. Considering our previous works related to polymersupported tin reagents, ${ }^{[39]}$ we then embarked in the adaptation of this reaction to the solid phase using organotin reagents grafted on an insoluble polystyrene matrix. Indeed these supported organotin reagents brings important advantages concerning the removal of tin byproducts from the reaction products which can be achieved by a simple filtration allowing less than $10 \mathrm{ppm}$ as total tin in the desired products. Due to the numerous applications of the tetrazole moiety, such strategy presents a major interest to obtain compounds of high purity. To the best of our knowledge, there is only a few cases where the tin mediated tetrazole synthesis has been developed with the aim to limit the amount of residual tin in the reaction product.

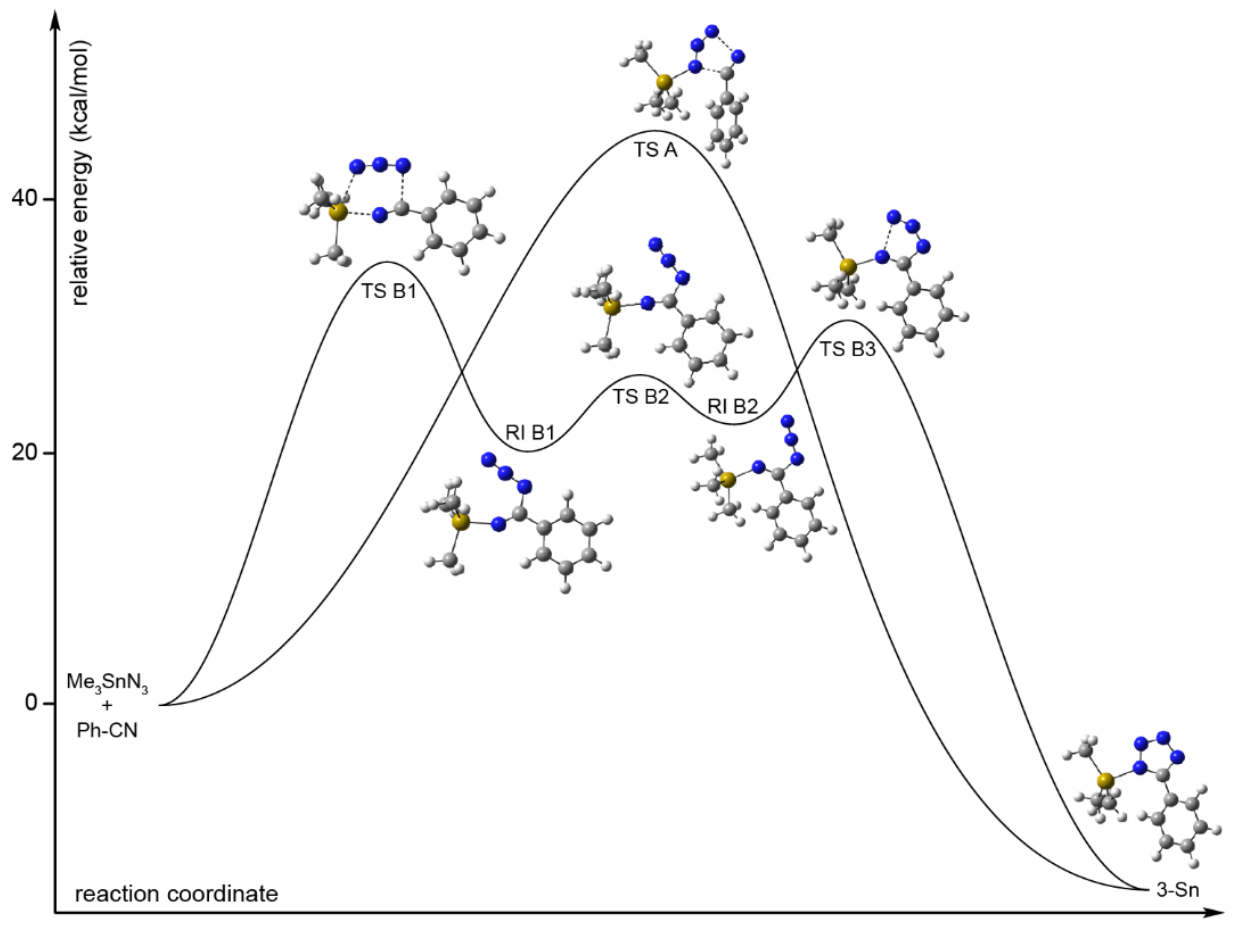

Figure 2. Free energy surface for the reaction between $\mathrm{Me}_{3} \mathrm{SnN}_{3}$ and benzonitrile (computed at the BMK/cc-pVDZ level of theory, geometries and individual energies are provided in the Supporting Information). Atom colour code: yellow for Sn, blue for $\mathrm{N}$, gray for $\mathrm{C}$ and white for $\mathrm{H}$. 
These processes concerns the use of a trioctyltin reagent to improve the partition between polar and unpolar compounds, ${ }^{[24]}$ or the use of a perfluoroalkyltin azide and a fluorous/organic liquid/liquid extraction. ${ }^{[25]}$ Otherwise, a crosslinked polystyrene-supported azidostannane has been recently reported with its use for the synthesis of aryl azides. ${ }^{[40]}$

According to our mechanistic studies, we required a polymer which was not temperature sensitive like Amberlite XE305, a commercially available macroporous polystyrene reticulated with 10-12\% of divinylbenzene. This polymer is resistant to abrasive effect induced by stirring and allow good loading $\left(\sim 1.5 \mathrm{mmol} . \mathrm{g}^{-1}\right)$. In addition, a tetramethylene spacer was required to minimize the steric hindrance both for trimethylsilyl azide / triorganotin alkoxide exchange and for addition of the azide on the nitrile. We prepared four different polymer-supported tin precatalysts P6-P9 having different steric hindrance around the tin atom. Briefly, the reaction sequence involves the lithiation of Amberlite XE305 followed by its reaction with 1-bromo-4-chlorobutane leading to polymer P1 (Scheme 5). A subsequent stannylation reaction with dialkylphenylstannyl lithium, afforded the stannylated polymers $\mathbf{P 2}{ }^{[41]}$ and $\mathbf{P 3}$ whose iododearylation with iodine in ethanol furnished polymers $\mathbf{P 4}$ and $\mathbf{P 5}$. Finally, a reaction with sodium hydroxide in methanol followed by reflux in dimethyl or diethylcarbonate during 18 hours led to supported organotin alkoxides P6-P9. The tin loading of $\mathbf{P 2}$ and $\mathbf{P 3}$ were found to be $1.2 \mathrm{mmol}^{-1}$ and $1.33 \mathrm{mmol.g} \mathrm{g}^{-1}$ respectively from tin ICP analyses and ${ }^{119} \mathrm{Sn}$ MAS NMR analyses of polymers P2-P9 pointed out an apparent quantitative conversion in every subsequent steps of these heterogeneous reactions.

Precatalysts P6-P9 were then involved in the synthesis of 5-substituted $1 \mathrm{H}$-tetrazoles for comparison with the results obtained with $\mathbf{2 a}$ and $\mathbf{2} \mathbf{b}$. We first evaluated the four polymer-grafted alkoxystannanes for the synthesis of $\mathbf{3 a}$ (Table 5).

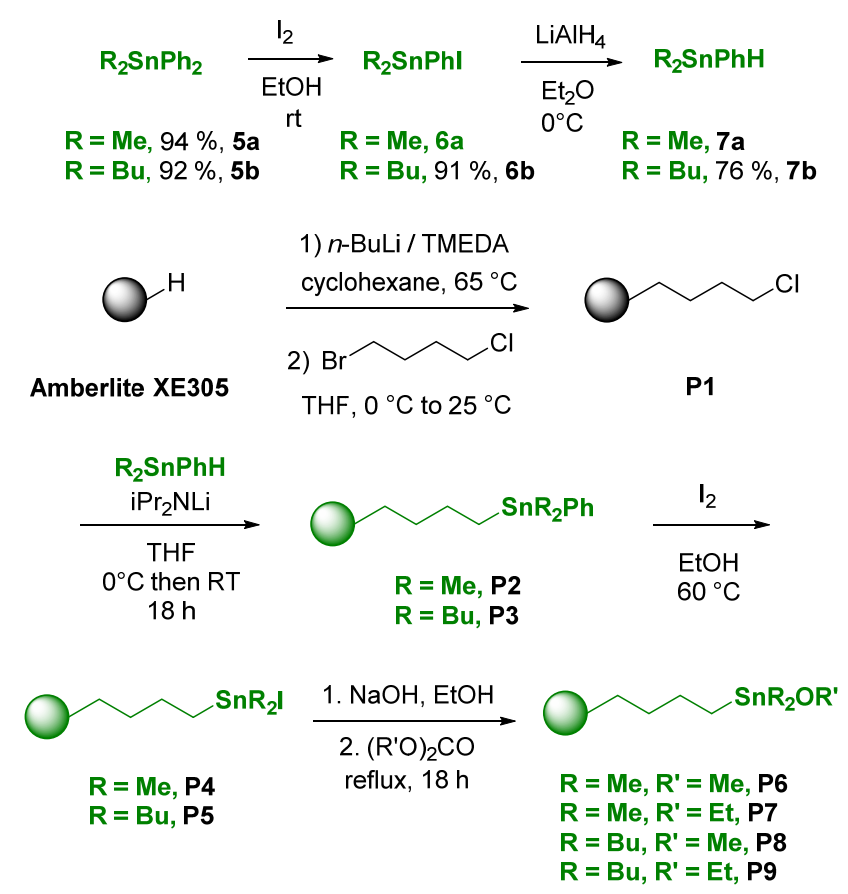

Scheme 5. Preparation of polymer-supported triorganotin alkoxides.

In the typical procedure, benzonitrile was reacted with $\mathrm{Me}_{3} \mathrm{SiN}_{3}$ in $\mathrm{Bu}_{2} \mathrm{O}$ in the presence of $10 \mathrm{~mol} \%$ of polymersupported organotin precatalyst at $140{ }^{\circ} \mathrm{C}$. Initial attempts with a reaction time of 4 hours only afforded moderate 
yields. Further studies reveal that good yields could be obtained by carrying out the reaction under reflux during 18 hours. This difference can be explained by the heterogeneous nature of the reaction involving catalysts P6P9, which usually lowers reaction kinetics. ${ }^{[39 f]}$ The reaction work-up used for these reactions was similar to those applied for homogeneous conditions but was preceded by a filtration to remove the insoluble supported organotin byproducts. By screening the four different catalysts, we observed that the less bulky was the alkoxide group of the precatalyst (P6 and P8), the higher was the reaction yield. We also noted that the replacement of two butyl groups linked to the tin atom by two methyl groups (P6 and P7) influenced more significantly the yield than the exchange of the ethoxy group by a methoxy group, a result in good agreement with the reaction mechanism which requires minimization of the steric hindrance to facilitates both the $\mathrm{Si}_{-} \mathrm{N}_{3} / \mathrm{Sn}$-OR exchange affording the effective active species and the addition reaction of the tin azide on the nitrile.

Table 5. Screening of the polymer supported organotin alkoxides for the synthesis of $\mathbf{3 a}$.

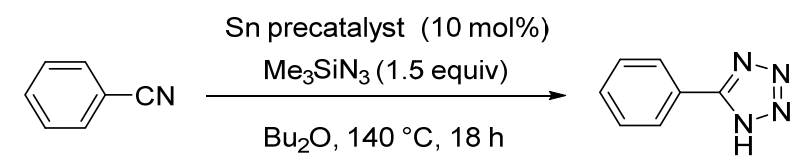

$1 \mathbf{a}$

$3 a$

\begin{tabular}{|c|c|c|c|}
\hline Entry & Sn precatalyst & & Yield $(\%)$ \\
\hline 1 & $\mathrm{SnMe}_{2} \mathrm{OMe}$ & P6 & 82 \\
\hline 2 & & P7 & 75 \\
\hline 3 & e & P8 & 70 \\
\hline 4 & $\mathrm{SnBu}_{2} \mathrm{OEt}$ & P9 & 68 \\
\hline
\end{tabular}

We next extended the reaction study involving precatalyst $\mathbf{P 6}$, and for this purpose a selection of both electron poor and electron rich aromatic nitriles was considered. The reaction procedure was similar to that applied to benzonitrile. Remarkably, very good yields were obtained indicating that these heterogeneous conditions do not affect significantly the catalytic system when the reaction time is prolonged from 4 hours to 18 hours (Table 6). In addition, after work-up and isolation of the reaction product, several analysis by ICP-MS were carried out and exhibited a low residual tin concentration (under $10 \mathrm{ppm}$ ) to be compared with a concentration of $1000 \mathrm{ppm}$ obtained with catalyst $\mathbf{2 a}$ or $\mathbf{2 b}$. This results points out the efficiency of this methodology which is compatible for the synthesis of pharmaceutical substances. ${ }^{[42]}$ 
Table 6. Synthesis of 5 -substituted $1 H$-tetrazoles promoted by polymer supported organotin alkoxides. ${ }^{[a],[b]}$

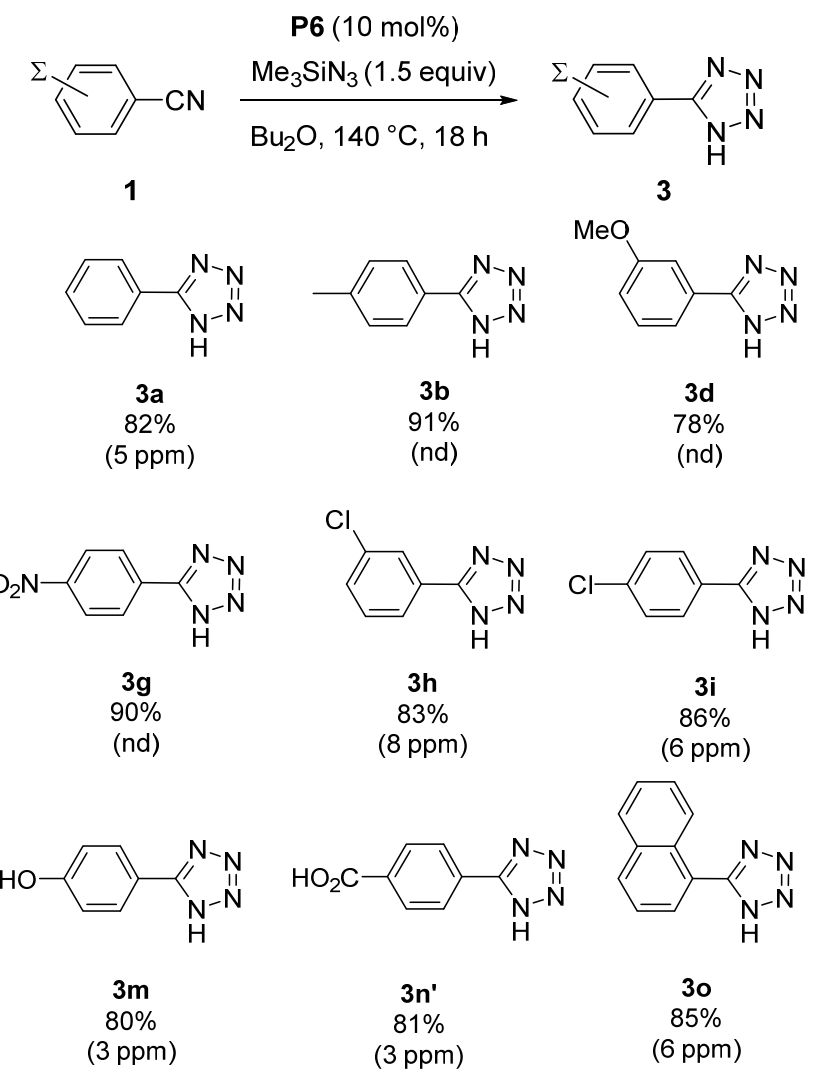

${ }^{[a]}$ Isolated yields; ${ }^{[b]}$ concentration in tin residues in the reaction product measured as total tin by ICP-MS; nd $=$ not determined

\section{Conclusion}

Triorganotin alkoxides were found to be efficient precatalysts for the synthesis of 5 -substituted $1 \mathrm{H}$-tetrazoles starting from nitriles and $\mathrm{Me}_{3} \mathrm{SiN}_{3}$ through the in situ generation of triorganotin azide. These precatalysts were found to be more efficient than dibutyltin oxide or tributyltin chloride often used for this reaction. The reaction scope is quite large, includes aryl and also alkyl nitriles and tolerates a wide variety of functional groups. The reaction mechanism is believed to proceed by a nucleophilic attack of the azide on the nitrile with a concomitant assistance of the tin on the nitrile nitrogen as suggested by Hammett relationship and quantum mechanical calculations. The mechanistic study underlines the importance of the polarization of the tin azide bond and of the steric hindrance both for trimethylsilyl azide / triorganotin alkoxide exchange and for addition of the azide on the nitrile. Finally, a heterogeneous version of the reaction has been developed and four polymer-supported organotin alkoxides have been prepared and evaluated as precatalysts for the reaction. The higher yields were obtained with the less hindered organotin alkoxide bearing a $\left(\mathrm{CH}_{2}\right)_{4}-\mathrm{SnMe}_{2} \mathrm{OMe}$ appendage. The 5-substituted $1 \mathrm{H}$-tetrazoles were prepared in high yields using this precatalyst and ICP-MS analyses confirmed the high efficiency of this procedure to avoid the presence of residual tin in the reaction products. 


\section{Experimental Section}

General procedure for the synthesis of 5-substituted-1H-tetrazoles 3 promoted by $2 a$. In a sealable tube, a solution of nitrile ( $2.5 \mathrm{mmol}$ ), trimethylsilyl azide ( $432 \mathrm{mg}, 497 \mu \mathrm{L}, 3.75 \mathrm{mmol})$, precatalyst $2 \mathbf{a}(80.3 \mathrm{mg}, 0.25 \mathrm{mmol})$ in dry dibutyl ether $(5$ $\mathrm{mL}$ ) was prepared and stirred for $4 \mathrm{~h}$ at $140^{\circ} \mathrm{C}$. The resulting mixture was cooled to $0^{\circ} \mathrm{C}$ and quenched with $5 \mathrm{~mL}$ of $\mathrm{NaOH}$ $(1 \mathrm{~N})$ and $15 \mathrm{~mL}$ of petroleum ether. The aqueous phase of the filtrate solution is separated from the organic one and acidified to $\mathrm{pH}=1$ at $0^{\circ} \mathrm{C}$ in order to obtain the tetrazole as a solid. After filtration, the solid was dried under vacuum. The procedure was similar when catalyst $\mathbf{2 b}$ was used, or when DMF was the solvent (reaction temperature $=150^{\circ} \mathrm{C}$ in this case).

General procedure for 5-substituted-1H-tetrazoles synthesis 3 promoted by P6-P9. A sealable tube was charged with polymer $\mathbf{P 6}$ or $\mathbf{P 7}$ ( $210 \mathrm{mg}$, tin loading $=1.2 \mathrm{mmol}_{\mathrm{g}} \mathrm{g}^{-1}, 0.1$ equiv), and purged by argon. Then, dibutyl ether $(5 \mathrm{~mL})$, nitrile ( $2.5 \mathrm{mmol}, 1$ equiv.), trimethylsilyl azide ( $432 \mathrm{mg}, 497 \mu \mathrm{L}, 3.75 \mathrm{mmol}, 1.5$ equiv) were introduced. The reaction mixture was stirred under orbital stirring and heated at $140^{\circ} \mathrm{C}$ under inert atmosphere during $18 \mathrm{~h}$. Then, petroleum ether $(15 \mathrm{~mL})$ and $1 \mathrm{M} \mathrm{NaOH}$ solution $(5 \mathrm{~mL})$ were added. The polymer was filtered and successively washed with a $1 \mathrm{M} \mathrm{NaOH}$ solution $(5 \mathrm{~mL})$, THF $(5 \mathrm{~mL})$ and finally petroleum ether $(5 \mathrm{~mL})$. The aqueous phase of the filtrate solution was separated from the organic one and acidified to $\mathrm{pH}=1$ at $0^{\circ} \mathrm{C}$ in order to obtain the tetrazole 3 as a solid. After filtration, the white solid was dried under vacuum. A similar procedure was used for the synthesis of 5-substituted-1H-tetrazoles catalyzed by $\mathbf{P 8}$ or $\mathbf{P 9}$ $\left(188 \mathrm{mg}\right.$, tin loading $\left.=1.33 \mathrm{mmol} \cdot \mathrm{g}^{-1}\right)$.

\section{Acknowledgements}

We gratefully acknowledge the Université de Nantes, the "Centre National de la Recherche Scientifique” (CNRS), Réseau de Recherche 2: “Aller vers une chimie éco-compatible”, the "Agence Nationale de la Recherche” (ANR) (grant 07JCJC0144), the Région Pays de la Loire (GREEN-SCO framework) for financial support. We also gratefully acknowledge Julie Hemez and Laurence Arzel for HRMS analyses and Isabelle Louvet for HPLC analyses. G.K. acknowledges the «Ministère de la Recherche et de l'Enseignement Supérieur » for a PhD grant.

\section{References}

[1] V. A. Ostrovskii, R. E. Trifonov, E. A. Popova, Russ. Chem. Rev. 2012, 61, 768-780.

[2] M. Baumann, I. R. Baxendale, S. V. Ley, N. Nikbin, Beilstein J. Org. Chem. 2011, 7, 442-495.

[3] a) C. Beier, J. Benting, D. Bernier, P. Y. Coqueron, P. Desbordes, C. Dubost, P. Genix, M. Ito, D. Portz, N. Sasaki, U. Wachendorff-Neumann, (Bayer CropScience), WO 2011134911 A2, 2011 ; b) F. Calo, M. Kordes, H. Kraus, T. Seitz, T. W. Newton, K. Kreuz, M. Pasternak, D. Massa, (BASF), WO 2015052173 A1, 2015 ; c) W. Krämer, U. Schrimer, P. Jeschke, M. Witschel, Modern Crop Protection Compounds, $2^{\text {nd }}$ ed., Wiley-VCH, Weinheim, 2012.

[4] a) T. M. Klapötke, in High Energy Density Materials (Ed.: T. M. Klapötke), Springer Berlin Heidelberg, Berlin, Heidelberg, 2007, pp. 85-121; b) R. P. Singh, R. D. Verma, D. T. Meshri, J. n. M. Shreeve, Chem. Rev. 2006, 45, 3584-3601; c) H. Gao, J. n. M. Shreeve, Chem. Rev. 2011, 111, 7377-7436; d) T. M. Klapötke, T. G. Witkowski, Propellants, Explosives, Pyrotechnics 2015, 40, 366-373.

[5] G. Aromí, L. A. Barrios, O. Roubeau, P. Gamez, Coord. Chem. Rev. 2011, 255, 485-546.

[6] a) A. J. A. Cobb, D. M. Shaw, D. A. Longbottom, J. B. Gold, S. V. Ley, Org. Biomol. Chem. 2005, 3, 84-96; b) D. A. Longbottom, V. Franckevicius, S. Kumarn, A. J. Oelke, V. Wascholowski, S. V. Ley, Aldrichimica Acta 2008, 41, 3-11; c) B. Maji, H. Yamamoto, Angew. Chem. Int. Ed. 2014, 53, 8714-8717.

[7] a) R. J. Herr, Bioorg. Med. Chem. 2002, 10, 3379-3394; b) N. A. Meanwell, J. Med. Chem. 2011, 54, $2529-2591$.

[8] a) V. B. Vangala, R. M. Hindupur, H. N. Pati, Int. J. Pharm. Research \& Review 2014, 3, 46-56; b) R. Vardanyan, V. J. Hruby, in Synthesis of Best Seller Drugs, Elsevier, Amsterdam, 2016, pp. 329-356.

[9] a) S. J. Wittenberger, Org. Prep. Proced. Int. 1994, 26, 499-531; b) G. I. Koldobskii, Russ. J. Org. Chem. 2006, 42 , 469 - 486; c) L. Myznikov, A. Hrabalek, G. I. Koldobskii, Chem. Hetereocycl. Compd. 2007, 43, 1-9; d) U. Bhatt, in Modern Heterocyclic Chemistry, Wiley-VCH Verlag GmbH \& Co. KGaA, 2011, pp. 1401-1430; e) J. Roh, K. Vávrová, A. Hrabálek, Eur. J. Org. Chem. 2012, 6101-6118.

[10] J.-P. Hagenbuch, Chimia 2003, 57, 773-776. 
[11] a) Z. P. Demko, K. B. Sharpless, J. Org. Chem. 2001, 66, 7945-7950; b) T. Jin, S. Kamijo, Y. Yamamoto, Tetrahedron Lett. 2004, 45, 9435-9438; c) T. Jin, F. Kitahara, S. Kamijo, Y. Yamamoto, Chem. Asian J. 2008, 3, 1575-1580; d) V. Aureggi, G. Sedelmeier, Angew. Chem. Int. Ed. 2007, 46, 8440-8444; e) J. Bonnamour, C. Bolm, Chem. Eur. J. 2009, 15,4543 - 4545.

[12] a) K. Sisido, K. Nabika, T. Isida, S. Kozima, J. Organomet. Chem. 1971, 33, 337-346; b) J. V. Duncia, M. E. Pierce, J. B. Santella, J. Org. Chem. 1991, 56, 2395-2400; c) F. A. J. Kerdesky, A. Haight, B. A. Narayanan, C. W. Nordeen, D. Scarpetti, L. S. Seif, S. Wittenberger, H. E. Morton, Synth. Commun. 1993, 23, 2027-2039; d) S. J. Wittenberger, B. G. Donner, J. Org. Chem. 1993, 58, 4139-4141.

[13] a) S. Aalla, G. Gilla, Y. Bojja, R. R. Anumula, P. R. Vummenthala, P. R. Padi, Org. Proc Res. Dev. 2012, 16, 682-686; b) A. Sampath, V. Prabhakar Reddy, A. Kalyan Chakravarthy, P. Pratap Reddy, Asian J. Chem. 2013, 25, 393-396.

[14] a) E. Le Grognec, J.-M. Chrétien, F. Zammattio, J.-P. Quintard, Chem. Rev. 2015, 115, 10207-10260; b) B. Delmond, G. Dumartin, in Solid State Organometallic Chemistry: Methods and Applications (Eds.: M. Gielen, R. Willem, B. Wrackmeyer), John Wiley \& Sons, Chichester, 1999, pp. 445-471; c) J.-M. Chrétien, J. D. Kilburn, F. Zammattio, E. Le Grognec, J.-P. Quintard, in Tin Chemistry - Fundamentals, Frontiers and Applications (Eds.: A. G. Davies, M. Gielen, K. H. Pannell, E. R. T. Tiekink), John Wiley \& Sons, Ltd, 2008, pp. 607-621; d) A. C. Albeniz, N. Carrera, Eur. J. Inorg. Chem. 2011, 2347-2360; e) C. Cordovilla, C. Bartolomé, J. M. Martínez-Ilarduya, P. Espinet, ACS Catalysis 2015, 5, 3040-3053.

[15] a) J. E. Leibner, J. Jacobus, J. Org. Chem. 1979, 44, 449-450; b) J. M. Berge, S. M. Roberts, Synthesis 1979, 471-472.

[16] E. Vedejs, S. M. Duncan, A. R. Haight, J. Org. Chem. 1993, 58, 3046-3050.

[17] N. A. Bumagin, L. I. Sukhomlinova, S. O. Igushkina, A. N. Vanchikov, T. P. Tolstaya, I. P. Beletskaya, Izv. Akad. Nauk, Ser. Khim. 1992, 2683-2685; Bull. Acad. Sci. USSR, Div. Chem. Sci. 1992, 2641, 2128-2129.

[18] a) D. P. Curran, S. Hadida, S.-Y. Kim, Z. Luo, J. Am. Chem. Soc. 1999, 121, 6607-6615; b) J. Otera, Acc. Chem. Res. 2004, 37, 288-296.

[19] J. Lipowitz, S. A. Bowman, J. Org. Chem. 1973, 38, 162-165.

[20] a) E. Fouquet, M. Pereyre, A. Rodriguez, T. Roulet, Bull. Soc. Chim. Fr. 1997, 134, 959-967; b) A. Hervé, A. L. Rodriguez, E. Fouquet, J. Org. Chem. 2005, 70, 1953-1956.

[21] J.-C. Poupon, D. Marcoux, J.-M. Cloarec, A. B. Charette, Org. Lett. 2007, 9, 3591-3594.

[22] A. Faurie, J. Grolleau, F. Gohier, M. Allain, S. Legoupy, P. Frère, Eur. J. Org. Chem. 2017, 2707-2714.

[23] a) H. Schumann, B. Pachaly, Angew. Chem. Int. Ed. 1981, 20, 1043-1044; b) T. Toupance, L. Renard, B. Jousseaume, C. Olivier, V. Pinoie, I. Verbruggen, R. Willem, Dalton Trans. 2013, 42, 9764-9770. T. Kato, Y. Shida, (Takeda Chemical Industries, Ltd.), EP 578125 A1, 1996.

[25] D. P. Curran, S. Hadida, S.-Y. Kim, Tetrahedron 1999, 55, 8997-9006.

[26] E. Le Grognec, J.-P. Quintard, G. Kerric, J.-M. Chrétien, F. Zammattio, (CNRS, Université de Nantes), WO 2013001235 A1, 2013.

[27] A. G. Davies, D. C. Kleinschmidt, P. R. Palan, S. C. Vasishtha, J. Chem. Soc. (C) 1971, 3972-3976.

[28] P. K. Kadaba, Synthesis 1973, 71-84.

[29] J. G. A. Luijten, M. J. Janssen, G. J. M. van der Kerk, Recl. Trav. Chim. Pays-Bas 1962, 81, 202-205.

[30] P. J. Smith, A. P. Tupčiauskas, Annual Reports on NMR Spectroscopy 1978, 8, 291-370.

[31] J. Wiss, A. Zilian, Org. Proc Res. Dev. 2003, 7, 1059-1066.

[32] S. J. Blunden, M. F. Mahon, K. C. Molloy, P. C. Waterfield, J. Chem. Soc. Dalton Trans. 1994, 2135-2143.

[33] J. Sýkora, V. Blechta, L. Soukupová, J. Schraml, Magn. Reson. Chem. 2008, 46, 1112-1118.

[34] W. von E. Doering, W. A. Henderson, J. Am. Chem. Soc. 1958, 80, 5274-5277.

[35] C. Hansch, A. Leo, R. W. Taft, Chem. Rev. 1991, 91, 165-195.

[36] a) F. Himo, Z. P. Demko, L. Noodleman, K. B. Sharpless, J. Am. Chem. Soc. 2002, 124, 12210-12216; b) F. Himo, Z. P. Demko, L. Noodleman, J. Org. Chem. 2003, 68, 9076-9080.

[37] D. Cantillo, B. Gutmann, C. O. Kappe, J. Am. Chem. Soc. 2011, 133, 4465-4475.

[38] H. Eyring, J. Chem. Phys. 1935, 3, 107-115.

[39] a) J.-M. Chrétien, F. Zammattio, E. Le Grognec, M. Paris, B. Cahingt, G. Montavon, J.-P. Quintard, J. Org. Chem. 2005, 70, 2870-2873; b) J.-M. Chrétien, F. Zammattio, D. Gauthier, E. Le Grognec, M. Paris, J.-P. Quintard, Chem. Eur. J. 2006, 12, 6816-6828; c) J.-M. Chrétien, A. Mallinger, F. Zammattio, E. Le Grognec, M. Paris, G. Montavon, J.-P. Quintard, Tetrahedron Lett. 2007, 48, 1781-1785; d) V. Fargeas, F. Zammattio, J.-M. Chrétien, M.-J. Bertrand, M. Paris, J.-P. Quintard, Eur. J. Org. Chem. 2008, 1681-1688; e) G. Fraboulet, V. Fargeas, M. Paris, J.-P. Quintard, F. Zammattio, Tetrahedron 2009, 65, 3953-3960; f) G. Kerric, E. Le Grognec, F. Zammattio, M. Paris, J.-P. Quintard, J. Organomet. Chem. 2010, 695, 103-110; g) G. Kerric, E. Le Grognec, V. Fargeas, F. Zammattio, J.-P. Quintard, M. Biesemans, R. Willem, J. Organomet. Chem. 2010, 695, 1414-1424.

[40] L. Godoy Prieto, M. J. Lo Fiego, A. B. Chopa, M. T. Lockhart, J. Organomet. Chem. 2017, 830, 26-32.

[41] The $\mathrm{SnMe}_{2} \mathrm{Ph}$ grafting is slightly contaminated by an $\mathrm{SnPh}_{2} \mathrm{Me}$ grafting, but after iododestannylation and alkoxylation steps, we consider that the efficiency of the obtained precatalyst will be only marginally modified when compared to pure Polymer$\left(\mathrm{CH}_{2}\right)_{4} \mathrm{SnMe}_{2} \mathrm{OR}$ '.

[42] M. M. Reddy, K. H. Reddy, M. U. Reddy, Pharmaceut. Reg. Affairs 2016, 5, 168-175. 
Tin-Catalyzed Synthesis of 5-Substituted $1 \mathrm{H}$ Tetrazoles from Nitriles:Homogeneous and Heterogeneous procedures

Adv. Synth. Catal. Year, Volume, Page - Page

Jean-Mathieu Chrétien, ${ }^{a}$ Gaelle Kerric, ${ }^{a}$ Françoise Zammattio, ${ }^{\mathrm{a}}$ Nicolas Galland, ${ }^{\mathrm{a}}$ Michael Paris, ${ }^{\mathrm{b}}$ Jean-Paul Quintard, ${ }^{\mathrm{a}}$ Erwan Le Grognec ${ }^{\mathrm{a}} *$

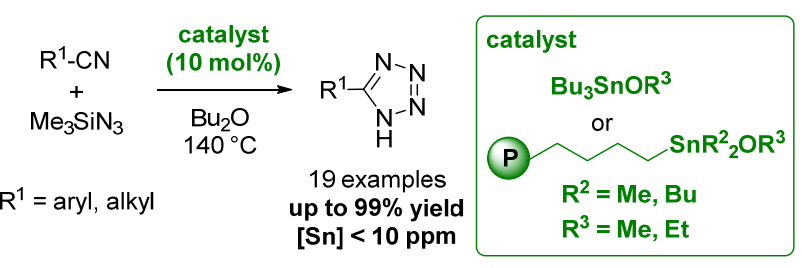

